\title{
No Time to Die: Can We Fix a Broken Cardiovascular Clock?
}

\author{
Simon Matskeplishvili Alexander Kalinkin \\ Medical Research and Education Center, Lomonosov Moscow State University, Moscow, Russia
}

Circadian (from Latin circā dièm - around a day) rhythms (CR) - the biological oscillations based upon our built-in diurnal clock - have a profound effect on human physiology and cellular functions. A master clock in the suprachiasmatic nucleus of the hypothalamus, or SCN, coordinates and synchronizes all the biological clocks in a living organism [1].

Historically, the first research of CRs was published in 1729 by a French astronomer Jean Jacques d'Ortous de Mairan [2]. He experimented with plants and sleep cycles and observed that the daily opening and closing of the leaves of a heliotrope plant in a dark room occurred without any exposure to sunlight. This proved that plants had intrinsic CR working regardless of lighting conditions.

For quite a long time, it was not clear whether the CR existed as a response to the external stimuli or whether there was an endogenous trigger behind physiological changes. It took many years of research until the Nobel Prize for Medicine in 2017 was awarded to Michael Young, Michael Rosbash and Jeffrey Hall for their discoveries of molecular mechanisms controlling the CR [3]. Genome-wide transcriptome, metabolome and proteome studies have significantly improved our understanding of the circadian regulation. In addition to the central clock, many fundamental "housekeeping" mechanisms were identified in different tissues.

Importantly, disorders of human biological clocks increase the risk of disease. These disturbances can arise from various sources and are important to identify as they can cause serious dysfunction in major internal systems or even increase the probability of many diseases including depression, stroke and cancer.

CRs continuously control our cardiovascular system through gene and protein manipulation resulting in the diurnal variation of cardiovascular events [4]. In the morning, heart rate, blood pressure, platelet reactivity, vasoconstriction and intra-arterial pressures increase after the night-time dip, coupled with endothelial dysfunction and decreased fibrinolysis. This leads to increased vulnerability of the cardiovascular system leading to acute cardiac events, such as sudden cardiac death, acute coronary syndrome, stroke, and ventricular arrhythmias [5].

The first analysis of such a relationship was performed by Schneider [6] in 1859 who investigated time and cause of death in 114,183 people who died in Berlin between January 1847 and December 1857. Only 126 years later, Muller et al. [7] published the first study on circadian variation of the incidence of cardiovascular events. Au- karger@karger.com

www.karger.com/crd

Karger $\stackrel{2}{=}$ (c) 2020 S. Karger AG, Basel
Simon Matskeplishvili, $\mathrm{MD}, \mathrm{PhD}$

Medical Research and Education Center, Lomonosov Moscow State University 27/10 Lomonosovsky prospect

Moscow 119234 (Russia)

simonmats@yahoo.com 
thors evidenced a marked CR in the frequency of onset of chest pain in 2,999 patients admitted with myocardial infarction with the peak from 6 a.m. to noon.

The first data from a large cohort and well-designed study on circadian variation in the incidence of sudden cardiac death was based on the Framingham Heart Study population by Willich et al. [8] observing a significant peak incidence of sudden cardiac death from 7 to 9 a.m. with a later decreased incidence between 9 a.m. and 1 p.m.

Many subsequent publications confirmed different variations in the incidence of cardiovascular disorders, for example, the morning peaks of ventricular tachyarrhythmias and myocardial infarction $[9,10]$. Interestingly, abnormal circadian blood pressure was linked to the development of non-ischaemic dilated cardiomyopathy [11]. Several important studies showed blunted circadian variations of vital parameters and absence of an early morning peak incidence of events in patients with severe disorders of the autonomic nervous system, chronic heart failure, diabetes mellitus, or when using various drugs, especially beta-blockers. On the contrary, Carson et al. [12] documented a non-uniform distribution of sudden deaths in patients with a heart failure with a PM peak but not an AM peak.

In their study published in Cardiology, Vicent et al. [13] aimed to determine the presence of a circadian pattern of death in hospitalized patients with cardiovascular diseases and to assess whether the circadian variation is different according to the specific cause of death. In our opinion the findings of the study are very important as they draw attention to periods of necessarily increased diurnal vigilance. The authors conclude that the observed biphasic pattern of mortality in hospitalized patients with cardiovascular diseases results from the disruption in the normal circadian rhythm due to drugs, comorbidities or artificial light exposure. We think that such an explanation of the oscillations in mortality has one significant limitation - it does not consider sleep and its disturbances.

Gami et al. [14] investigated the correlation between obstructive sleep apnoea and the risk of sudden cardiac death in a large population of 10,701 adults referred for polysomnography at the Mayo clinic sleep disorders centre. In their study, patients with sleep-disordered breathing had a peak in sudden cardiac death during the sleeping hours in contrast to the nadir of sudden death during this period in people without obstructive sleep apnoea and in the general population. In addition, some part of the morning peak may also be related to the sleep disor- ders or due to transition from sleep state to the wake state.

Another important study was performed by Aboyans et al. [15] suggesting a potential relationship between sleep apnoea and the morning excess rate of non-fatal myocardial infarctions. The authors related the morning peak and the paradoxical low rate of events during the night in patients with sleep-related breathing disorders to the changes in sympathetic activity rather than to the direct role of hypoxemia.

We suggest that the biphasic pattern for cardiovascular and non-cardiovascular deaths in the study of Vicent et al. [13] may be related to such an unrecognized risk factor as sleep impairment. After completing routine morning medical procedures, followed by food intake and various medications often including sedative drugs, the sleep disorders and first of all abnormal sleep-related breathing may be a key aetiological factor of severe events. Discoordination between peripheral clocks due to external environment could potentially underlie the development of sleep disorders. Circadian clocks and sleep are intertwined processes and obviously disruption of the latter alters the circadian timing system.

Further studies are needed with the focus on sleep disorders as a risk factor in circadian variation of the incidence of cardiovascular disorders. Elucidation of the interplay between molecular clocks in each cardiovascular organ and abnormal sleep might help us establish a novel therapeutic approach for cardiovascular disorders. Overall, we are witnessing a transformation in the field of circadian medicine in its translational approach to human health. The possibility of pharmacological reactivation of circadian mechanisms may revolutionize the way in which treatment is provided and these new discoveries may finally give us a clue on how to fix a broken cardiovascular clock.

\section{References}

1 Panda $\mathrm{S}$. The arrival of circadian medicine. Nat Rev Endocrinol. 2019 Feb;15(2):67-9.

2 De Mairan J. Observation botanique. Paris: Histoire de l'Académie Royale Des Sciences; 1729. pp. 35-6.

3 Burki T. Nobel Prize awarded for discoveries in circadian rhythm. Lancet. 2017 Oct; 390(10104):e25-6.

4 Muller JE, Mangel B. Circadian variation and triggers of cardiovascular disease. Cardiology. 1994;85 Suppl 2:3-10.

5 Takeda N, Maemura K. Circadian clock and the onset of cardiovascular events. Hypertens Res. 2016 Jun;39(6):383-90. 
6 Schneider C. Ein Beitrag zur Ermittlung der Sterblichkeits-Verhältnisse in Berlin nach den Todeszeiten. Arch Pathol Anat Physiol Klin Med. 1859;16(1-2):95-119.

7 Muller JE, Stone PH, Turi ZG, Rutherford JD, Czeisler CA, Parker C, et al. Circadian variation in the frequency of onset of acute myocardial infarction. N Engl J Med. 1985 Nov; 313(21):1315-22.

8 Willich SN, Levy D, Rocco MB, Tofler GH, Stone PH, Muller JE. Circadian variation in the incidence of sudden cardiac death in the Framingham Heart Study population. Am J Cardiol. 1987 Oct;60(10):801-6.

9 Tofler GH, Gebara OC, Mittleman MA, Taylor P, Siegel W, Venditti FJ Jr, et al.; The CPI Investigators. Morning peak in ventricular tachyarrhythmias detected by time of implantable cardioverter/defibrillator therapy. Circulation. 1995 Sep;92(5):1203-8.
10 Ruwald MH, Moss AJ, Zareba W, Jons C, Ruwald AC, McNitt S, et al. Circadian distribution of ventricular tachyarrhythmias and association with mortality in the MADIT-CRT trial. J Cardiovasc Electrophysiol. 2015 Mar; 26(3):291-9.

11 Sawamura A, Okumura T, Takeshita K, Watanabe N, Kano N, Mori H, et al. Abnormal circadian blood pressure profile as a prognostic marker in patients with nonischemic dilated cardiomyopathy. Cardiology. 2017;136(1):1-9.

12 Carson PA, O'Connor CM, Miller AB, Anderson S, Belkin R, Neuberg GW, et al. Circadian rhythm and sudden death in heart failure: results from Prospective Randomized Amlodipine Survival Trial. J Am Coll Cardiol. 2000 Aug;36(2):541-6.
13 Vicent L, González-Casal D, Bruña V, Devesa C, García-Carreño J, Sousa-Casasnovas I, et al. Circadian rhythm of deaths in a Cardiology department: a five years analysis. Cardiology. DOI:10.1159/000505682.

14 Gami AS, Olson EJ, Shen WK, Wright RS, Ballman KV, Hodge DO, et al. Obstructive sleep apnea and the risk of sudden cardiac death: a longitudinal study of 10,701 adults. J Am Coll Cardiol. 2013 Aug;62(7): 610-6.

15 Aboyans V, Cassat C, Lacroix P, Tapie P, Tabaraud F, Pesteil F, et al. Is the morning peak of acute myocardial infarction's onset due to sleep-related breathing disorders? A prospective study. Cardiology. 2000;94(3): $188-92$. 